\title{
Telemedicine Services for Emerging Adults with Type 1 Diabetes
}

\author{
Neesha Ramchandani \\ New York University Rory Meyers College of Nursing, New York, NY, US
}

E merging adults with type 1 diabetes (T1D) often find it challenging to manage their diabetes well due to the many competing priorities they are juggling during this time. The majority of emerging adults (72\%) are already looking for health information online, so telemedicine may be an avenue to explore with them. Telemedicine services for individuals with T1D are becoming increasingly popular and have been found to be beneficial for those who use them. However, there are very few multi-component telemedicine services available for individuals with T1D, and none of them provide a comprehensive technology-based system. Additionally, while these multi-component T1D telemedicine systems often included emerging adults in the group under study, the average age of the study subjects was usually above the age range of emerging adulthood. This suggests that specific developmental needs of emerging adults are not being addressed by these telemedicine systems, nor are the issues faced by diverse populations. More research needs to be done to address which telemedicine services, if any, would be beneficial for this especially vulnerable population.

\section{Key Words}

Type 1 diabetes, emerging adults, technology, telemedicine, telehealth, internet healthcare delivery

Disclosures: Neesha Ramchandani has nothing to declare in relation to this article.

Acknowledgments: Neesha Ramchandani would like to thank Dr Susan Sullivan-Bolyai and Dr Gail D'Eramo Melkus for their editorial assistance and other input on this manuscript, and the Jonas Center for Nursing and Veterans Healthcare for funding the dissertation project from which this was extracted.

Review Process: Double-blind peer review.

Authorship: The named authors meets the criteria of the International Committee of Medical Journal Editors for authorship for this manuscript, takes responsibility for the integrity of the work as a whole and has given final approval for the version to be published.

open Access: This article is published under the Creative Commons Attribution Noncommercial License, which permits any non-commercial use, distribution, adaptation and reproduction provided the original author(s) and source are given appropriate credit. (c) The Authors 2018.

Received: September 21, 2018

Accepted: November 6, 2018

Citation: US Endocrinology. 2018;14(2):73-6

Corresponding Author: Neesha Ramchandani, Rory Meyers College of Nursing, $4331^{\text {st }}$ Avenue, $6^{\text {th }}$ floor, New York, NY 10010, USA. E: neesha.ramchandani@gmail.com

Support: No funding was received for

the publication of this manuscript.
Emerging adulthood, which encompasses those who are 18-30 years old, has been defined as a period of identity exploration, instability, self-focus, feeling in-between, and a time filled with optimism where anything seems possible. ${ }^{1-4}$ During this development individuals establish independence, define who they are, and make important educational and vocational choices. ${ }^{1-5}$ Emerging adults with type 1 diabetes (T1D) often find it challenging to manage their diabetes effectively due to the many priorities they are juggling during this time..$^{5-10}$ It is possible that technology may help keep them engaged with their diabetes providers during this highly transitional period. This review provides an overview of the outcomes and limitations of multi-component telemedicine services that have been used with emerging adults with T1D over the past 10 years.

\section{Mobile device and mobile internet use}

The majority of emerging adults (72\%) are already looking for health information online. ${ }^{11}$ Rates of mobile internet use and the use of mobile devices are highest in this age group and have been rising over the past decade. ${ }^{11}$ A Pew research study (2010) on mobile internet use in American teenagers and young adults identified that in the age group 18-29 years old, 93\% go online, 93\% own a cell phone, $66 \%$ own a laptop or netbook, and $81 \%$ are wireless internet users. ${ }^{11}$ Internet-based healthcare delivery is a novel way to target unmet needs in this population. ${ }^{12}$ This technologically-savvy group ${ }^{11}$ has the potential to greatly benefit from a multi-component, technology-based diabetes self-management (DSM) intervention that closes the gaps in their healthcare services while meeting their individual needs. ${ }^{12}$

\section{Benefits of telemedicine}

Telemedicine services which utilize the internet, videoconferencing services, and apps to enhance diabetes care and self-management for individuals with T1D, are becoming increasingly popular. Glycemic and psychologic outcomes from telemedicine visits are equivalent to, or better than, in-person visits for both children and adults with T1D. ${ }^{13-17}$ Additional benefits of telemedicine are increased attendance at visits, 12,13 less time spent traveling to and attending visits, 15,16,18 and lower cost. ${ }^{15,16}$ In addition, the use of telemedicine versus in-person visits does not affect the therapeutic relationship between providers and adolescent patients, ${ }^{19}$ and may actually empower patients to better manage their diabetes. ${ }^{15,18}$ 


\section{A review of existing telemedicine systems for emerging adults with type 1 diabetes}

While several telemedicine systems exist, very few multi-component T1D telemedicine systems targeting emerging adults have been described in the literature, and those that are reported are not fully comprehensive technology-based systems. . $^{15-18,20-25}$ Additionally, demographic data on race or ethnicity were not presented in any of the papers reviewed. Unless specified below, these studies took place in diabetes centers with largely white populations in the United States and Europe. A summary of these studies also appears in Table 1.

EncoDiab, a virtual community that includes DSM tools (carbohydrate counter, insulin dose calculator, and body mass index calculator), a library, and a chat room for chatting with peers and providers, was designed based on user feedback. ${ }^{20}$ However, it targeted 18-50-year-olds and not specifically emerging adults..$^{20}$ The average age of the user was 34 years old, suggesting that even though EncoDiab represents a system designed by patients, it may not suffice specifically for emerging adults with T1D because it may not address emerging-adult-specific issues. Additionally, it does not contain a videoconferencing component.

In the TeleDiab 1 study, Diabeo - a smartphone app with an electronic logbook, a bolus calculator, automatic algorithms that can be used to make insulin dose or carbohydrate intake adjustments, and automatic data transmission to the diabetes clinicians' computers-helped to improve glycemic control in a sample of 180 adults with T1D. ${ }^{16}$ After 6 months of use, glycated hemoglobin ( $\mathrm{HbA1C}$ ) had improved from $9.07 \pm 1.07 \%$ at baseline to $8.63 \pm 1.07 \%$ in subjects who only used the app ( $p=0.022)$ and $8.41 \pm 1.07 \%$ in subjects who used the app and also received supplemental phone calls from their diabetes clinician every 2 weeks $(p=0.0019)$. No change in HbA1C was seen in the control group ( $9.10 \pm 1.16 \%, p=N S)$. The app did not contain an education piece; any education the subjects received during this study was given by the diabetes clinicians during the phone calls. There was also no videoconferencing as part of the study. ${ }^{16}$ Similar to the EncoDiab study, ${ }^{20}$ the average age of subjects in the Diabeo study was 34 years old, suggesting that the outcomes of this study may not be representative of what may be found with emerging adults.

A post-hoc analysis of the Diabeo study analyzed subjects by high and low app use. ${ }^{17}$ Low users had $36 \%$ system use initially, and use decreased over the 6 months of the study. More emerging adults fell into the "lower user" category: low users' median age was 25 years old versus a median age of 33 years old for high users $(p=0.086)$. Information about subjects' race/ethnicity, academic status, living situation, and profession were not given by app use group. The metabolic improvements that were seen in low users (HbA1C improved from $9.0 \%$ to $8.5 \%$, p-value not given) were attributed to the app facilitating communication with diabetes clinicians. ${ }^{17}$

The Medical Guard Diabetes (MGD) telemedicine system that was used in the Telemed study allowed automatic downloading of blood glucose meters directly into a secure website. It also allowed users to annotate the blood glucose readings and enter insulin dose and carbohydrate intake information. ${ }^{15}$ MGD was used in conjunction with monthly "telematic" visits and required feedback from diabetes clinicians within 3 days of a subject uploading diabetes data into the system. The "telematic" visits were not defined, and based on other telemedicine literature, could range from phone calls to videoconferencing. All subjects in the study had improvements in HbA1C after 6 months of study participation ( $\mathrm{HbA} 1 \mathrm{C}=9.2 \%$ at baseline and $8.6-8.7 \%$ at end of study, $p=N S$ between groups but $p<0.001$ endpoint versus baseline), increased knowledge about their diabetes, and increased adherence to DSM tasks. Additionally, subjects in the intervention group spent significantly less time attending visits (353 \pm 222 minutes versus $823 \pm 645$ minutes, $p<0.0001$, travel time included) and required significantly less time from the diabetes team ( $232 \pm 89$ minutes versus $288 \pm 105$ minutes, $p<0.001)$. Furthermore, a lack of face-to-face encounters appeared to empower subjects to better manage their diabetes..$^{15}$ As in the EncoDiab ${ }^{20}$ and Diabeo studies, ${ }^{16}$ the average age of study subjects was approximately 32 years old, suggesting that despite its benefits, this system may not specifically address the needs of emerging adults with T1D.

Two other pilot studies evaluated satisfaction and usability of different telemedicine systems. The first, a virtual clinic designed for insulin pump users, offered subjects access to their health information, communication with healthcare providers via email and "ask the expert" sessions, and interaction with peers. ${ }^{21}$ The system did not have videoconferencing, nor was it clear if there was an electronic logbook for blood glucose, insulin, and carbohydrate data. Users found participation in the virtual clinic reassuring; however, only $50 \%$ of subjects used the system at least weekly. The peer interaction piece was seen as the most valuable component (by $53 \%$ of subjects), followed by communication with healthcare providers (by $41 \%$ ), and access to health information (by 24\%). Subjects ranged in age from 2270 years old, but were likely not emerging adults, as the average duration of diabetes was 24 years. ${ }^{21}$

The second described a telemedicine system with both patient and provider platforms that was designed in Iran for use in developing countries where there is limited access to diabetes providers. ${ }^{22}$ The patient platform contained a logbook, data management capabilities, educational reading materials, that had been developed based on need and that had some embedded animations, and ways to contact the endocrinologist and the web administrator. The provider platform contained a list of patients who had updated records or messaged the endocrinologist, patient diabetes and demographic/medical data including data analysis capabilities, prescribing and medical advice (this was not further clarified), and a place to change their password. The system sent the providers email notifications if a patient had entered new data or if new messages had been sent to them. Most study participants were satisfied with the system. Of note, the system did not include any videoconferencing services and it had limited data entry based on the needs of the patient population being studied. Furthermore, it was presented to parents of pediatric patients with T1D and emerging adults with T1D, but the two groups' results were not separated, presumably because of the small sample size.22

The majority of telemedicine services described in the empirical literature are aimed towards either children, adolescents, or adults. Only one telemedicine consultation service specifically targeting emerging adults (18-25 years old) with T1D, entitled Colorado Young Adults with Type 1 Diabetes (COYOT1) Clinic, has been reported in the literature, to date. ${ }^{18,23}$ It is also the only multi-component telemedicine system in the literature that is based in the United States. This year-long study employed videoconferencing services instead of in-person visits for three of the four American Diabetes Association-recommended quarterly follow-up visits and enabled peer support through video-based group visits. Study participants uploaded 
Table 1: Summary of existing telemedicine systems for emerging adults with type 1 diabetes

\begin{tabular}{|c|c|c|c|c|c|c|}
\hline Author & $\begin{array}{l}\text { Study } \\
\text { name }\end{array}$ & Description & $\begin{array}{l}\text { Average age } \pm \\
\text { SD (Range) }\end{array}$ & $\begin{array}{l}\mathrm{N}, \\
\% \text { male }\end{array}$ & Outcomes & Limitations \\
\hline $\begin{array}{l}\text { Raymond } \\
\text { et al. }(2016)^{18} \\
\text { Reid et al. } \\
(2018)^{23}\end{array}$ & CoYoT1 & $\begin{array}{l}\text { Videoconferencing services with } \\
\text { diabetes providers instead of } \\
\text { in-person visits; } \\
\text { peer support through video-based } \\
\text { group visits; study participants } \\
\text { uploaded insulin pumps, BG meters, } \\
\text { and CGMs immediately prior to } \\
\text { their visit }\end{array}$ & $\begin{array}{l}\text { Control group } \\
20.5 \pm 1.9 \\
\text { Intervention } \\
\text { group } \\
19.8 \pm 1.7 \\
(18-25)\end{array}$ & $\begin{array}{l}\mathrm{N}=81 \\
\text { Control group } \\
49 \% \mathrm{M} ; \\
\text { Intervention group } \\
45 \% \mathrm{M}\end{array}$ & $\begin{array}{l}\text { Intervention group: } \\
\text { significantly increased } \\
\text { attendance at visits; } \\
\text { greater satisfaction with } \\
\text { the care they received }\end{array}$ & $\begin{array}{l}\text { Not a randomized controlled } \\
\text { trial—study participants } \\
\text { self-selected which group they } \\
\text { were in }\end{array}$ \\
\hline $\begin{array}{l}\text { Alvarado- } \\
\text { Martel et al. } \\
(2015)^{20}\end{array}$ & EncoDiab & $\begin{array}{l}\text { Virtual community that includes DSM } \\
\text { tools, a library, and a chat room }\end{array}$ & $34(18-50)$ & $\begin{array}{l}\mathrm{N}=33 \\
54.5 \% \mathrm{M}\end{array}$ & System development & $\begin{array}{l}\text { No videoconferencing } \\
\text { component; } \\
\text { may not address issues } \\
\text { specific to emerging adults }\end{array}$ \\
\hline $\begin{array}{l}\text { Charpentier } \\
\text { et al. }(2011)^{16}\end{array}$ & TeleDiab 1 & $\begin{array}{l}\text { Diabeo app use (electronic logbook, } \\
\text { bolus calculator, automatic algorithms } \\
\text { for insulin dose or carbohydrate } \\
\text { adjustments, and automatic data } \\
\text { transmission to the diabetes } \\
\text { clinicians' computers) } \pm \text { supplemental } \\
\text { phone calls }\end{array}$ & $33.8 \pm 12.9$ & $\begin{array}{l}\mathrm{N}=180 \\
36.7 \% \mathrm{M}\end{array}$ & $\begin{array}{l}\text { Statistically significant } \\
\text { improvement in HDA1C } \\
\text { in those who used the } \\
\text { app; } \\
\text { further improvement } \\
\text { in HbA1c with } \\
\text { supplemental phone } \\
\text { calls }\end{array}$ & $\begin{array}{l}\text { No videoconferencing } \\
\text { component; } \\
\text { no education component in } \\
\text { the app; } \\
\text { may not address issues } \\
\text { specific to emerging adults }\end{array}$ \\
\hline $\begin{array}{l}\text { Esmatjes } \\
\text { et al. }(2014)^{15}\end{array}$ & Telemed & $\begin{array}{l}\text { Used the Medical Guard Diabetes } \\
\text { system (allowed automatic } \\
\text { downloading of BG meters directly } \\
\text { into a secure website, annotation } \\
\text { of BG readings, and insulin dose } \\
\text { and carbohydrate intake entry) } \\
\text { in conjunction with monthly } \\
\text { "telematic" visits }\end{array}$ & $\begin{array}{l}\text { Control group } \\
31.5 \pm 9.0 \text {; } \\
\text { Intervention } \\
\text { group } \\
32.2 \pm 10.1\end{array}$ & $\begin{array}{l}\mathrm{N}=154 \text {, } \\
\text { Control group } \\
47.4 \% \mathrm{M} \text {; } \\
\text { Intervention group } \\
42.4 \% \mathrm{M}\end{array}$ & $\begin{array}{l}\text { Significant improvement } \\
\text { in HDA1c, increased } \\
\text { knowledge about their } \\
\text { diabetes, and increased } \\
\text { adherence to DSM tasks } \\
\text { in all subjects; } \\
\text { decreased time } \\
\text { attending visits and } \\
\text { less time required } \\
\text { from diabetes team in } \\
\text { intervention group }\end{array}$ & $\begin{array}{l}\text { "Telematic" visits not defined; } \\
\text { may not address issues } \\
\text { specific to emerging adults }\end{array}$ \\
\hline $\begin{array}{l}\text { Powell et al. } \\
(2009)^{21}\end{array}$ & & $\begin{array}{l}\text { Virtual clinic designed for insulin } \\
\text { pump users that offered access to } \\
\text { health information, communication } \\
\text { with health care providers via email } \\
\text { and "ask the expert" sessions, and } \\
\text { interaction with peers }\end{array}$ & NR (22-70) & $\begin{array}{l}\mathrm{N}=17 \\
\% \mathrm{M} \mathrm{NR}\end{array}$ & $\begin{array}{l}\text { Users found } \\
\text { participation in the } \\
\text { virtual clinic reassuring; } \\
\text { peer interaction piece } \\
\text { seen as the most } \\
\text { valuable component }\end{array}$ & $\begin{array}{l}\text { No videoconferencing } \\
\text { component; } \\
\text { unclear if there was an } \\
\text { electronic logbook; } \\
\text { may not address issues } \\
\text { specific to emerging adults- } \\
\text { average duration of diabetes } \\
\text { was } 24 \text { years }\end{array}$ \\
\hline $\begin{array}{l}\text { Ayatollahi } \\
\text { et al. }(2016)^{22}\end{array}$ & & $\begin{array}{l}\text { Telemedicine system with both patient } \\
\text { and provider platforms designed for } \\
\text { use in developing countries where } \\
\text { there is limited access to diabetes } \\
\text { providers. } \\
\text { Patient platform: logbook, data } \\
\text { management capabilities, educational } \\
\text { reading materials with embedded } \\
\text { animations, and ways to contact } \\
\text { the endocrinologist and the web } \\
\text { administrator; } \\
\text { Provider platform: list of patients } \\
\text { who had updated their records or } \\
\text { messaged the endocrinologist, patient } \\
\text { diabetes and demographic/medical } \\
\text { data, data analysis capabilities, } \\
\text { prescribing and medical advice }\end{array}$ & NR & $\begin{array}{l}\text { Phase } 1: \mathrm{N}=30 \\
\text { (7children/patients, } \\
23 \text { parents). } \\
\text { Phase 2: } \\
15 \text { endocrinologists } \\
\text { \%M NR in either } \\
\text { group }\end{array}$ & System development & $\begin{array}{l}\text { No videoconferencing } \\
\text { component; } \\
\text { limited data entry based on the } \\
\text { needs of the patient population } \\
\text { being studied; } \\
\text { presented to parents of } \\
\text { pediatric patients with T1D and } \\
\text { emerging adults with T1D but } \\
\text { the two groups' results were } \\
\text { not separated; } \\
\text { may not address issues } \\
\text { specific to emerging adults }\end{array}$ \\
\hline
\end{tabular}


their insulin pumps, blood glucose meters, and continuous glucose monitors immediately prior to their visit so the data could be reviewed by the diabetes provider. The intervention managed to engage emerging adults with T1D in their care for the 1 year of study. There was a significant increase in attendance at visits in the intervention group $(p<0.0001)$ both compared to the control group and to themselves in the year before they participated in the study. This result was clinically meaningful as well: 74\% of individuals in the intervention group attended four visits during the year of study, while no one in the control group attended four visits during the same period of time. Furthermore, those in the intervention group reported greater satisfaction with the care they received. ${ }^{18,23}$

Additionally, a mobile phone service that successfully reduced the incidence of diabetic ketoacidosis in emerging adults with poorly controlled $\mathrm{T}_{1}{ }_{1}{ }^{24}$ and a review of apps that had the potential to support safe drinking practices in this age group but were not used for that purpose, ${ }^{25}$ have been described. No other literature discussing telemedicine services specifically for emerging adults was found.

\section{Diabetes technology use-clinical outcomes}

Users of diabetes technology (apps, etc.) have reported high levels of satisfaction with such systems. .12, $^{21}$ Increased use of such technology is strongly correlated with improved diabetes management, including improved knowledge about diabetes and improved DSM behaviors such as blood glucose monitoring and insulin administration..$^{26}$ Information on any observed improvements in glycemic control were not presented, but it follows that glycemic control should improve based on the improvement in DSM behaviors. However, technology is not being utilized on a regular basis in the transition-aged patient population (13-25 years old), ${ }_{1}^{27}$ and when used, the use of these services wanes over time. ${ }^{21}$ Additionally, high attrition in telemedicine services for T1D (up to 37\% in a group who were $92 \%$ white) has been reported, ${ }^{28,29}$ though one program (COYOT1) was able to keep their study participants engaged with their diabetes care team over the course of 1 year using videoconferencing services. ${ }^{18,23}$ Any interactive technology aimed at enhancing diabetes care and self-management needs to be developmentally appropriate to the patient's age, abilities, sensitivities, lifestyle, and cultural nuances in order to have a chance to be successful. ${ }^{30}$

\section{Summary}

Emerging adults with T1D often find it challenging to manage their diabetes well because of the many competing priorities they are juggling during this time. Since they are already high users of the internet and mobile internet, telemedicine may help them keep them engaged with their diabetes providers during this highly transitional period. There are very few multi-component telemedicine services available for individuals with T1D, and none of them provide a comprehensive technology-based system. An electronic logbook, education services, a messaging service with providers (text/e-mail/etc.), videoconferencing for follow-up visits, and social networking with peers have all been included in these systems, and each of these components was found to be beneficial. However, no one system that has been described in the literature contained all components. Additionally, while these multi-component T1D telemedicine systems often included emerging adults in the group under study, the average age of the study subjects was usually above the age range of emerging adulthood. The one study that focused on creating a service for emerging adults (COYOT1) did not include any variations for cultural diversity or for differing needs throughout emerging adulthood. This suggests that specific developmental needs of emerging adults are not being addressed by these telemedicine systems, nor are issues faced by diverse populations. More research needs to be done to address which telemedicine services, if any, would be beneficial for this especially vulnerable population.
1. Arnett JJ. Emerging Adulthood: The Winding Road From the Late Teens Through the Twenties. New York: Oxford University Press, 2004

2. Anderson BJ, Wolpert HA. A developmental perspective on the challenges of diabetes education and care during the young adult period. Patient Educ Couns. 2004;53:347-52.

3. Arnett JJ. A Longer Road to Adulthood. In: Emerging Adulthood: The Winding Road From the Late Teens Through the Twenties. New York: Oxford University Press, 2004:1-3

4. Hanna KM. A framework for the youth with type 1 diabetes during the emerging adulthood transition. Nurs Outlook. 2012;60:401-10.

5. Wafa S, Nakhla M. Improving the transition from pediatric to adult diabetes healthcare: a literature review. Can I Diabetes. 2015;39:520-8.

6. Peters A, Laffel L. Diabetes care for emerging adults: recommendations for transition from pediatric to adult diabetes care systems: a position statement of the American Diabetes Association, with representation by the American College of Osteopathic Family Physicians, the American Academy of Pediatrics, the American Association of Clinical Endocrinologists, Pediatrics, the American Association of Clinical Endocrinologists, the American Osteopathic Association, the Centers for Disease Control and Prevention, Children with Diabetes, Society, the International Society for Pediatric and Adolescent Diabetes, Juvenile Diabetes Research Founda the National Diabetes Education Program, and the Pediatic Endocrine Society (formerly Lawson Wilkins Pediatric Endocrine Society). Diabetes Care. 2011:34:2477-85.

7. Majumder E, Cogen FR, Monaghan M. Self-management strategies in emerging adults with type 1 diabetes. J Pediat Health Care. 2017;31:29-36.

8. Pyatak E. Participation in occupation and diabetes self-management in emerging adulthood. Am J Occup Ther. 2011;65:462-9.

9. Hill S, Gingras $\rfloor$ Gucciardi E. The lived experience of Canadian university students with type 1 diabetes mellitus. Can J Diabetes. 2013;37:237-42.
10. Wilson V. Students' experiences of managing type 1 diabetes. Paediatr Nurs. 2010;22:25-8.

11. Lenhart A, Purcell K, Smith A, Zickuhr K. Social Media \& Mobile Internet Use among Teens and Young Adults, 2010. Available at: wuw.pewinternet.org/wp-content/uploads/sites/9/media/Files/ Reports/2010/PIP_Social_Media_and_Young_Adults_Report_ Final_with_toplines.pdf (accessed November 8, 2018).

12. Mayor S. Use texts, apps, and Skype to keep young people with diabetes engaged with services, says guidance. BMJ. 2016;352:i394.

13. Wood $\mathrm{CL}$, Clements SA, McFann K, et al. Use of telemedicine to improve adherence to American Diabetes Association standards in pediatric type 1 diabetes. Diabetes Technol Ther. 2016;18:7-14

14. Duke DC, Wagner DV, Ulrich J, et al. Videoconferencing for teens with diabetes: family matters. J Diabetes Sci Technol. 2016;10:816-23.

15. Esmatjes $E$, Jansà $M$, Roca $D$, et al. The efficiency of telemedicine to optimize metabolic control in patients with type 1 diabetes mellitus: Telemed study. Diabetes Technol Ther. 2014;16:435-41.

16. Charpentier G, Benhamou PY, Dardari D, et al. The Diabeo software enabling individualized insulin dose adjustments combined with telemedicine support improves $\mathrm{HbA} 1 \mathrm{c}$ in poorly controlled type 1 diabetic patients: a 6-month, randomized, open-label, parallel-group, multicenter trial (TeleDiab 1 Study). Diabetes Care. 2011:34:533-9.

17. Franc S, Borot S, Ronsin O, et al. Telemedicine and type 1 diabetes: is technology per se sufficient to improve glycaemic control? Diabetes Metab. 2014:40:61-6.

18. Raymond JK, Berget CL, Driscoll KA, et al. CoYoT1 Clinic: innovative telemedicine care model for young adults with type 1 diabetes. Diabetes Technol Ther. 2016;18:385-90.

19. Freeman KA, Duke DC, Harris MA. Behavioral health care for adolescents with poorly controlled diabetes via Skype: does working alliance remain intact? J Diabetes Sci Technol. 2013;7:727-35.
20. Alvarado-Martel D, Cañas F, Velasco R, et al. Design, construction, and implementation of an online platform for patients with type 1 diabetes: EncoDiab. Patient Prefer Adherence. 2015:9.767-75.

21. Powell J, Jennings $A$, Armstrong $N$, et al. Pilot study of a virtual diabetes clinic: satisfaction and usability. J Telemed Telecare 2009;15:150-2.

22. Ayatollahi H, Hasannezhad M, Fard HS, Haghighi MK. Type 1 diabetes self-management: developing a web-based telemedicine application. Health Inf Manag. 2016:45:16-26.

23. Reid MW, Krishnan S, Berget C, et al. CoYoT1 Clinic: home telemedicine increases young adult engagement in diabetes care Diabetes Technol Ther. 2018;20:370-9.

24. Farrell K, Holmes-Walker DJ. Mobile phone support is associated with reduced ketoacidosis in young adults. Diabet Med. 2011;28:1001-4

25. Tamony $\mathrm{P}, \mathrm{Holt} \mathrm{R}, \mathrm{Barnard} \mathrm{K}$. The role of mobile applications in improving alcohol health literacy in young adults with type 1 diabetes: help or hindrance? J Diabetes Sci Technol. 2015:9:1313-20.

26. Harrison S, Stadler M, Ismail K, et al. Are patients with diabetes mellitus satisfied with technologies used to assist with diabetes management and coping?: A structured review. Diabetes Techno Ther. 2014;16:771-83.

27. Los E, Ulrich J, Guttmann-Bauman I. Technology use in transition-age patients with type 1 diabetes: reality and promises I Diabetes Sci Technol. 2016:10:662-8.

28. Balkhi AM, Reid AM, Westen SC, et al. Telehealth interventions to reduce management complications in type 1 diabetes: A review. World J Diabetes. 2015;6:371-9.

29. Mulvaney SA, Rothman RL, Wallston KA, et al. An internet-based program to improve self-management in adolescents with type 1 diabetes. Diabetes Care. 2010;33:602-4.

30. Fitzner K, Moss G. Telehealth--an effective delivery method for diabetes self-management education? Popul Health Manag. 2013;16:169-77. 